ESAIM: COCV 28 (2022) 28

https://doi.org/10.1051/cocv/2022012
ESAIM: Control, Optimisation and Calculus of Variations

www.esaim-cocv.org

\title{
ERRATUM TO "WELL-POSEDNESS OF EVOLUTIONARY NAVIER-STOKES EQUATIONS WITH FORCES OF LOW REGULARITY ON TWO-DIMENSIONAL DOMAINS"
}

\author{
ESAIM: COCV 27 (2021) 61, https://doi.org/10.1051/cocv/2021058
}

\section{Eduardo Casas ${ }^{1}$ AND Karl KunisCh ${ }^{2, *}$}

Received November 26, 2021. Accepted February 3, 2022.

In this erratum, the authors correct an error in Theorem 2.9 of [1]. That paper focuses on the Navier-Stokes equations

$$
\left\{\begin{array}{l}
\frac{\partial \mathbf{y}}{\partial t}-\nu \Delta \mathbf{y}+(\mathbf{y} \cdot \nabla) \mathbf{y}+\nabla \mathfrak{p}=\mathbf{f} \text { in } Q=\Omega \times I \\
\operatorname{div} \mathbf{y}=0 \text { in } Q, \mathbf{y}=0 \text { on } \Sigma=\Gamma \times I, \mathbf{y}(0)=\mathbf{y}_{0} \text { in } \Omega
\end{array}\right.
$$

under sufficiently low regularity assumptions in such a way that measure-valued forcing functions $f$ in the spatial variable are admitted. Here $I=(0, T)$ with $0<T<\infty$, and $\Omega \subset \mathbb{R}^{d}$ denotes a connected bounded domain with a $C^{3}$ boundary $\Gamma$, Concerning the notation we refer to [1]. Let us only recall that $\mathbf{B}_{s, r}(\Omega)=$ $\left(\mathbf{W}_{s^{\prime}}(\Omega)^{\prime}, \mathbf{W}_{s}(\Omega)\right)_{1-1 / r, r}$ denotes real interpolation spaces for $r, s \in(0, \infty)$.

In Theorem 2.9 of [1] we present the following result. Its proof contains a flaw which is corrected below.

Theorem 0.1. Let us assume that $q \geq 8, p \in\left(\frac{4}{3}, 2\right), \mathbf{f} \in L^{q}\left(I ; \mathbf{W}^{-1, p}(\Omega)\right)$, and $\mathbf{y}_{0}=\mathbf{y}_{N 0}+\mathbf{y}_{S 0} \in \mathbf{B}_{2,4}(\Omega)+$ $\mathbf{B}_{p, q}(\Omega)$. Then the variational solution $\mathbf{y}$ of $(0.1)$ belongs to $L^{q}\left(I ; \mathbf{L}^{4}(\Omega)\right)$ and depends continuously in this topology on $\mathbf{f}$ and $\mathbf{y}_{0}$. Moreover, the estimate

$$
\|\mathbf{y}\|_{L^{q}\left(I ; \mathbf{L}^{4}(\Omega)\right)} \leq \eta_{q}\left(\|\mathbf{f}\|_{L^{q}\left(I ; \mathbf{W}^{-1, p}(\Omega)\right)}+\left\|\mathbf{y}_{S 0}\right\|_{\mathbf{B}_{p, q}(\Omega)}+\left\|\mathbf{y}_{N 0}\right\|_{\mathbf{B}_{2,4}(\Omega)}\right)
$$

holds for an increasing monotone function $\eta_{q}:[0, \infty) \longrightarrow[0, \infty)$ independent of $\mathbf{f}$ and $\mathbf{y}_{0}$, with $\eta_{q}(0)=0$.

\footnotetext{
${ }^{1}$ Departmento de Matemática Aplicada y Ciencias de la Computación, E.T.S.I. Industriales y de Telecomunicación, Universidad de Cantabria, 39005 Santander, Spain.

${ }^{2}$ Institute for Mathematics and Scientific Computing, University of Graz, Heinrichstrasse 36, 8010 Graz, Austria.

* Corresponding author: karl.kunisch@uni-graz.at
} 
Proof. We can follow the proof in $[1]$ up to $\mathbf{W}_{4,2}(0, T) \subset C\left([0, T] ;\left(\mathbf{H}^{-1}(\Omega), \mathbf{H}_{0}^{1}(\Omega)\right)_{\frac{3}{4}, 4}\right)$. Then we observe that $\left(\mathbf{H}^{-1}(\Omega), \mathbf{H}_{0}^{1}(\Omega)\right)_{\frac{3}{4}, 4} \subset \mathbf{L}^{4}(\Omega)$. Indeed, by $([2]$, p. 186,317$)$ we have $\left(\mathbf{H}^{-1}(\Omega), \mathbf{H}^{1}(\Omega)\right)_{\frac{3}{4}, 4}=\mathbf{B}_{2,4}^{\frac{1}{2}}(\Omega)$, where $\mathbf{B}_{2,4}^{\frac{1}{2}}(\Omega)$ denotes a Besov space. Further the continuous embedding $\mathbf{B}_{2,4}^{\frac{1}{2}}(\Omega) \subset \mathbf{L}^{4}(\Omega)$ holds, see page 328 of [2]. Since $\mathbf{H}_{0}^{1}(\Omega) \subset \mathbf{H}^{1}(\Omega)$, is a closed subspace, the inclusion $\left(\mathbf{H}^{-1}(\Omega), \mathbf{H}_{0}^{1}(\Omega)\right)_{3 / 4,4} \subset\left(\mathbf{H}^{-1}(\Omega), \mathbf{H}^{1}(\Omega)\right)_{3 / 4,4}$ follows. Combining these facts we find $\left(\mathbf{H}^{-1}(\Omega), \mathbf{H}_{0}^{1}(\Omega)\right)_{\frac{3}{4}, 4} \subset \mathbf{L}^{4}(\Omega)$, and $\mathbf{W}_{4,2}(0, T) \subset C\left([0, T] ; \mathbf{L}^{4}(\Omega)\right)$ follows. We can now return to the proof in [1] to obtain the desired result.

Acknowledgements. We would like to thank Prof. G. Peralta, who pointed out the mistake in the original version.

\section{REFERENCES}

[1] E. Casas and K. Kunisch, Well-posedness of evolutionary Navier-Stokes equations with forces of low regularity on two-dimensional domains. ESAIM: COCV $\mathbf{2 7}$ (2021) 61.

[2] H. Triebel, Interpolation Theory, Function Spaces, Differential Operators. North-Holland, Berlin (1978).

\section{Subscribe to Open (S2O) A fair and sustainable open access model}

This journal is currently published in open access under a Subscribe-to-Open model (S2O). S2O is a transformative model that aims to move subscription journals to open access. Open access is the free, immediate, online availability of research articles combined with the rights to use these articles fully in the digital environment. We are thankful to our subscribers and sponsors for making it possible to publish this journal in open access, free of charge for authors.

\section{Please help to maintain this journal in open access!}

Check that your library subscribes to the journal, or make a personal donation to the $\mathrm{S} 2 \mathrm{O}$ programme, by contacting subscribers@edpsciences.org

More information, including a list of sponsors and a financial transparency report, available at: https://www.edpsciences.org/en/maths-s2o-programme 